\title{
Principal Support is Imperative to the Retention of Teachers in Hard-to-Staff Schools
}

\author{
Amy L Hughes ${ }^{1}$, John J. Matt ${ }^{2}$, Frances L. O’Reilly ${ }^{2}$ \\ ${ }^{1}$ Department of Special Education, Western Governors University, Salt Lake City, Utah \\ ${ }^{2}$ Department of Educational Leadership, the University of Montana, Missoula, Montana \\ Correspondence: John J. Matt, 32 Campus Dr., Department of Educational Leadership, the University of Montana, \\ Missoula, Montana 59812, USA.
}

$\begin{aligned} & \text { Received: November 21, } 2014 \\ & \text { Accepted: December 3, } 2014 \quad \text { Online Published: December 24, } 2014 \\ & \text { doi:10.11114/jets.v3i1.622 }\end{aligned} \quad$ URL: http://dx.doi.org/10.11114/jets.v3i1.622

\begin{abstract}
Teacher retention is an ongoing problem in hard-to-staff schools. This research examined the relationship between principal support and retention of teachers in hard-to-staff schools. The purpose of this study was to, (a) to determine the relationship between teacher retention and principal support, (b) to examine the perception of support between teachers and principals and how these perceptions affect teacher retention in hard-to-staff schools, and (c) to discover if there is a correlation between the principal's supports and teacher retention. The participants were both administrators and teachers who are currently employed. A non-experimental correlational design was used in which principals and teachers in hard-to-staff schools were surveyed regarding the role of principal supports in the retention of teachers. Findings in this study posited, personal growth and the ability to receive support from administrators regarding emotional, environmental and instructional support had an impact on a teacher's decision to stay or leave in hard-to-staff schools. Participant teachers provided insight as to which forms of support they valued most from their principals. The recommendations guide administrators working in hard-to-staff schools to reduce teacher attrition and are also intended to encourage leaders to look more closely at their programs and their own styles of leadership and support. Specific recommendations are made for administrators, institutions, and teachers.
\end{abstract}

Keywords: hard-to-staff schools, principal support, teacher retention

\section{Introduction}

Many of the students in correctional and residential facilities exhibit challenging behaviors therefore teaches in these facilities face daily challenges with students exhibiting emotional and behavioral problems. George and George (1995) posited, "Among specific groups of special educators, attrition rates are particularly high for teachers of students with emotional and behavioral disorders" (p. 228). For this study, hard-to-staff schools will be classified as schools that are located in correctional or residential facilities and comprise a high number of students with emotional and/or behavioral needs. A high number of hard-to-staff schools require their teaching staff is certified in special education, as most of the student population served suffers from emotional/behavioral disorders. Teachers consider many factors when deciding where they would like to teach. Brown and Wynn (2009) found that the more difficult working conditions found in hard-to-staff schools decrease the attractiveness of teaching relative to alternative occupations or activities that teachers might pursue. The purpose of this study was to: (a) determine the relationship between teacher retention and principal support, (b) to examine the perception of support between teachers and principals and how these perceptions affect teacher retention in hard to staff schools, and (c) to discover if there is a correlation between the principal's supports and teacher retention.

\section{Research Questions}

This study addressed the areas of support principals provide for teachers that are perceived to be essential to increase teacher retention in such schools. The following research questions and hypothesis were the foundation of the study:

$\mathrm{Q}_{1}$ : Do principals' supportive behaviors correlate with the retention of teachers who work in hard-to-staff schools?

$\mathrm{Q}_{2}$ : What is the relationship between teacher and principal support scores on the Administrative Support Survey? 
$\mathrm{Q}_{3}$ : Is grade level a factor in the perceived support of teachers?

$\mathrm{H}_{1}$ : Principals' support skills are related to teacher retention.

$\mathrm{H}_{2}$ : Principals will perceive they provide greater support to the teachers than the teachers will acknowledge on the survey.

$\mathrm{H}_{3}$ : Teachers working in multi-level (K-12) institutions will report having more support from their principals than teachers working in institutions with only high school (9-12) level students.

\section{Delimitations}

This study is delimited to a single western state in the United States. Additionally, it is delimited to those principal and teacher respondents holding the appropriate educational license and endorsement, that work in hard-to-staff schools throughout the state that are recognized in the National Association of Therapeutic Schools and Programs (NATSAP) Directory and the schools recognized in the Northwest Accreditation Commission (NWAC).

\section{Literature Review}

Retention of teachers in public education has been a topic of study for many years. There is a limited number of studies focusing specifically on retention and recruitment in hard-to-staff schools. Varrati, Lavine and Turner, (2009) found beginning teachers view principals as key figures for "support and guidance" (p. 481). According to Darling-Hammond (2003), keeping good teachers should be one of the most important agenda items for any school leader. This is especially true for placements in urban areas, facilities and correctional settings. Principals play a vital part in improving teacher retention by providing support in the following domains (environmental, instructional, technical and emotional). As the building's instructional leader, school principals reinforce the institutional culture by providing guidance and support and offering instructional and institutional resources. There are many factors that contribute to and inhibit teacher retention. However, there is little research in regards to retention of teachers in hard-to-staff placements. According to Berry (2004), "little is known about recruiting and retaining teachers for hard-to-staff schools" (p. 7), thus adding to the complexity of why teachers leave their placements and the need for this study. In research prior to Berry's findings, Cooley and Yovanoff (1996) also found that while we know more about what causes teachers to leave, what we know much less about is "what would constitute effective interventions to prevent or alleviate burnout and improve retention among this high risk group of professionals" (p. 338) working in hard-to-staff placements.

Cooley and Yovanoff (1996) discovered that there is a strong correlation between job satisfaction and actual turnover; and employees who experience job burnout may not quit their employment but cost the district through "declining job performance, absenteeism" (p. 343). Billingsley and Cross (1992) reported that job satisfaction and intent to stay in the field is associated with "greater leadership support, more work involvement, and lower levels of role conflict and stress" (p. 465). Otto and Arnold (2005) found that when administrative support was "perceived by the special education teacher to be present, it was considered an incentive for retention; and the absence of administrative support was considered a cause for leaving the profession" (p. 255).

\section{Research Design}

A non-experimental correlational design was chosen because it allows for a relationship between variables to be established and studied without manipulation of the participants (Cozby, 2007). A survey was used to obtain information from the participants. The participants responded regarding their experiences of perceive support, received support, and how they feel support affects teacher retention. Support, as used in this study, was defined as the principal taking an active role in assisting, encouraging, and displaying approving attitudes towards teachers. In addition, the participants were asked how important is this kind of support for them to stay or leave their positions. The four domains of support being researched are: emotional, technical, instructional, and environmental supports.

A pilot survey was conducted prior to the study. The purpose of the pilot study was to "reveal whether or not participants [understood] the instructions" (Cozby, 2007, p. 181) and to further validate the instrument to be used. A therapeutic school which was not included in the study served as the pilot test site. The pilot survey participants consisted of five teachers and the framework of the pilot survey consisted of survey administration, collection, review of the data, and holding a focus group to discuss any changes that needed to be made to ensure clarity of questions and procedures. The use of the pilot study and focus group provided insight for ensuring the quality and validity of the survey.

An important component of the research design is the ethical considerations and confidentiality. The research was conducted with the utmost regard to the participants both in the pilot study and the actual survey research. As part of the ethical and confidential considerations of the research, an informed consent letter was included with the survey. Confidentiality was also addressed with the participants to explain their rights with the survey, such as the option to opt out at any time and how their responses will remain anonymous in the reporting of data with no identifiers attached to their surveys. 


\section{Measurements/Instruments}

The instrument used in this study was the Administrative Support Survey, by C. Yvonne Balfour, 2001, George Mason University. Dr. Balfour granted her permission and also provided counsel on the use of the survey. The survey was developed by Balfour in 2001, to measure administrative supports expected and received by novice special education teachers. After piloting the survey the final draft was constructed and sent out in 2001. Methods of reconstructing the survey included gleaning information from the literature review, conducting interviews and holding several focus groups to develop the most accurate and pertinent survey for this study (Balfour, 2001). The final draft version of the survey was then sent out to determine the reliability of the instrument. Changes that were made to survey included formatting and improving clarity in the questions (Balfour, 2001). The Chronbach Alpha for Balfour's instrument was reported at .60 or greater for the eight subscales and .80 or greater for the two total scores. The reliability coefficients for the subscales (70-93) and the total scores (.90 and .91). These coefficients (.60 or greater) indicate the instrument is reliable.

\section{Population and Data Analyses}

Invitations to participate in the survey were sent out to 20 sites within a western state that fit the delimitations of the research. Each of these sites had an educational component that included an administrator and teachers, but the number of teachers varied from site to site. The sample size was 20 sites. The administrators were asked how many teachers were employed within their school. The total sample size of eligible participants (teachers) was 80.

Analyses from the survey were conducted using the steps that Creswell (2003) recommends to ensure accurate and informative data analyses. The five steps contained (a) information on the number of surveys returned and numbers of those not returned, (b) methods of response bias, (c) descriptive analysis, (d) the instrument used, and (e) statistical procedures. The Spearman Rho Correlation (Rho) was used to explore relationships among the variables (Pallant, 2007). Due to the nature of the Likert scale, a non-parametric alternative is the best fit. A conservative approach was considered prudent for this study thus the Spearman Rho Correlation was used. The variables in this study were used as measures.

When the survey was closed, a total of 17 out of 20 administrators had responded which resulted in an $85 \%$ return rate. Forty-one of the 80 teachers eligible to participate returned surveys with a response rate of $51.25 \%$.

\section{Analyses}

The focus of Research Question 1 was to determine the relationship, if any, between principal supports and the retention of teachers in hard-to-staff schools. The results showed that teachers who were expecting to stay in their current assignment for the 2012-2013 school year held the four areas of support very high in relation to why they were continuing to stay in their current placement. The area of support that had the highest correlation was that of emotional support, and the second highest was environmental support, followed by instructional support and finally technical support. The data provided by teachers that were sure that they would not be in their current placement next school year also showed a strong correlation between retention and support. This data showed that all areas of support affect whether or not the teachers were planning on staying in their current placement. The lack of support for these teachers impacted their choice to leave their current placement. The final category was teachers who were not sure if they were going to stay in their current placement. The results showed there was not any specific area of support that influenced whether or not these teachers were going to stay (see Table 1).

Table 1. Teachers total support scores based upon decision to stay or leave current placement)

\begin{tabular}{|c|c|c|c|}
\hline Teacher Support Scale & $\begin{array}{l}\text { Staying in current } \\
\text { placement }\end{array}$ & Leaving current placement & $\begin{array}{l}\text { Not sure of staying in } \\
\text { current placement }\end{array}$ \\
\hline & $\begin{array}{l}\text { Correlation } \\
\text { Coefficient/Sig. } 2 \text { tailed }\end{array}$ & $\begin{array}{l}\text { Correlation Coefficient/Sig. } \\
2 \text { tailed }\end{array}$ & $\begin{array}{l}\text { Correlation Coefficient/Sig. } \\
2 \text { tailed }\end{array}$ \\
\hline Emotional & $.707 * *$ & $1.0^{* *}$ & .200 \\
\hline Environmental & $.633 * *$ & $1.0^{* *}$ & .400 \\
\hline Instructional & $.419 *$ & $1.0 * *$ & 400 \\
\hline Technical & $.374 * *$ & $1.0^{* *}$ & 1.0 \\
\hline
\end{tabular}

*Correlation significant at the 0.05 level $* *$ Correlation significant at the 0.01 level

Research Question 2 examined the relationship between support scores of the administrators and teachers of hard-to-staff schools. The teachers were asked to answer the survey questions based upon the support they felt they received from their 
administrators. The administrators were asked to answer the question based upon the support they felt they provided to their teachers. The results of the data provided showed that principals perceived that they supported their teachers better than the teachers perceive they were supported by the principals (see Table 2). The area that showed the greatest difference in views of perceived support was that of instructional support.

Table 2. Completed layout of data presented: Difference in Total Support Scores of Teachers and Principals

\begin{tabular}{llll}
\hline Support Scale & Principal Scores & Teacher Scores & Difference \\
\hline Emotional & 70.333 & 64.567 & 5.766 \\
Environmental & 47.000 & 40.055 & 6.945 \\
Instructional & 47.583 & 35.171 & 12.412 \\
Technical & 41.833 & 34.514 & 7.319 \\
\hline
\end{tabular}

Finally, Research Question 3 sought to determine the relationship between principal and teacher support in relation to what grade level they worked in. Data showed that all areas of support were reported to be important to all teachers in all grade levels. The data also showed that principals working in (K-12) and (9-12) schools felt they provided a good deal of support to all their teachers (see Table 3).

Table 3. Completed layout of data presented: Principal and Teacher Support Scores in Relation to Grade Level and Support Received/Given

\begin{tabular}{|c|c|c|c|c|c|c|c|c|}
\hline \multirow{2}{*}{$\begin{array}{l}\text { Principal/Teacher Support } \\
\text { Scale }\end{array}$} & \multicolumn{4}{|c|}{ Grades 9-12 } & \multicolumn{4}{|c|}{ Multilevel K-12 } \\
\hline & \multicolumn{2}{|c|}{ Given } & \multicolumn{2}{|c|}{ Perceived } & \multicolumn{2}{|c|}{ Given } & \multicolumn{2}{|c|}{ Perceived } \\
\hline & \multicolumn{2}{|c|}{$\begin{array}{l}\text { Correlation } \\
\text { Coefficient/Sig. } \\
2 \text { tailed }\end{array}$} & \multicolumn{2}{|c|}{$\begin{array}{l}\text { Correlation } \\
\text { Coefficient/Sig. } 2 \\
\text { tailed }\end{array}$} & \multicolumn{2}{|c|}{$\begin{array}{l}\text { Correlation } \\
\text { Coefficient/Sig. } 2 \\
\text { tailed }\end{array}$} & \multicolumn{2}{|c|}{$\begin{array}{l}\text { Correlation } \\
\text { Coefficient/Sig. } 2 \\
\text { tailed }\end{array}$} \\
\hline Emotional & $1.0 *$ & - & $.593^{*}$ & .025 & $.806^{*}$ & .009 & $.723 * *$ & .000 \\
\hline Environmental & $1.0^{*}$ & - & $.593 *$ & .025 & $.806^{*}$ & .009 & $.574 * *$ & .005 \\
\hline Instructional & $1.0^{*}$ & - & $.822 * *$ & .001 & .328 & .310 & $.827 * *$ & .000 \\
\hline Technical & $1.0^{*}$ & - & $.789 * *$ & .001 & .259 & .500 & $.596 * *$ & .003 \\
\hline $\begin{array}{l}\text { Total Number } \\
\text { Participants }\end{array}$ & $\mathrm{n}=3$ & & $\mathrm{n}=14$ & & $\mathrm{n}=9$ & & $\mathrm{n}=22$ & \\
\hline
\end{tabular}

*Correlation is significant at the 0.01 level ** Correlation is significant at the 0.05 level

\section{Findings and Conclusions}

Data evinced from this study found support of teachers has a critical and important impact on teacher retention in hard-to-staff schools. Teachers that participated in this study provided insight as to which forms of support they valued most from their principals. All of the areas of support were considered important. However, the areas of emotional and environmental support were rated the highest. Several participants made comments such as "positive feedback-she doesn't give any" to "always available when I need him." A principal modeled emotional support by supporting a teacher's decision in front of parents and colleagues. In addition, a principal who made a teacher feel like they make a difference by supporting activities within teacher's classrooms contributed to a teacher wanting to stay employed in their current positions. Teachers felt supported when principals recognized them for a job well done. Teachers with few instances of individual recognition were more apt to leave the field than those who were praised individually.

Personal growth and the ability to receive support from administrators regarding emotional, environmental and instructional support had an impact on a teacher's decision to stay or leave in hard-to-staff schools. The value of communication and being notified of events in their buildings was also very important to the teachers. This type of support, emotional, environmental and instructional, points to the notion that respondents want to be valued within the school system.

Findings of this study also demonstrated principals and teachers in hard-to-staff schools have different perceptions of teachers' support. Principals' perceived their support for teachers was greater than the support the teachers felt they received. The differences in these views of support could potentially have a negative effect on teacher retention in hard -to-staff schools. 


\section{Recommendations for Principals, Teachers, and Policy Planners in Hard-to-Staff Schools}

It is critical for principals to understand the impact their support has on their teachers. Participants indicated systemic structures were barriers to the ability of principals to support teachers. Principals must be able to work within the leadership structure of the institution to provide the necessary tools for their staff to succeed, and reduce the possibility of teacher attrition in hard-to-staff schools.

Participants recommendations included: (a) having more curriculum and planning time, (b) receiving more positive feedback and recognition for a job well done, (c) salary increases, (d) more opportunities for professional development, and (e) adequate staff to meet the needs of the students. It has been found in previous research that all of these factors play an important role in the retention of teachers in hard-to-staff schools (Billingsley, 2004).

Principals have the opportunity to create and maintain a positive school culture and climate that ensures a reduction of teacher attrition in hard-to-staff schools. An important aspect of creating this type of positive environment is to provide teachers an ample amount of positive support. The majority of these hard-to-staff schools, especially the ones in this study, have a student population that is comprised of emotionally disturbed students. These students can be challenging and teacher interactions are critical within these populations. What this means for teachers is that they are prone to mental exhaustion, difficult behaviors, and stressful workdays. One participant stated, "sometimes frustrations become overwhelming" Ax, Conderman and Stephens (2001) stated, "principals who are in touch with these daily realities can provide the individualized support needed to reduce their teacher's feelings of isolation, exhaustion, and burnout" (p. 68). Principals that recognize the difficulty of the job will have better success retaining teachers.

A principal's main staple for improving support and having schools with a positive culture is communication. So many of the ideas and barriers can be overcome and achieved by communication. Building bonds of trust and creating teacher leadership with a shared vision can improve the retention of teachers in hard-to-staff schools.

A collaborative principal-teacher relationship is important and must include open forums, discussions, meetings, and reviews to evaluate the needs of the school, teachers and students. In addition, teachers need to be aware of their own well-being. They need to step back from the stress of hard-to-staff schools and decrease the likelihood of burnout. This could include attending workshops designed to decrease stress and burnout.

Teachers could also take an active role in improving their support systems through mentoring programs. Creating programs in hard-to-staff schools that allow teachers to engage with each other and process the day-to-day struggles and successes, could potentially bolster support.

Policy planners in hard-to-staff schools can also benefit from these recommendations. One of the ways to help teacher retention in hard-to-staff schools would be to increase the ratio of administrators to teachers. Several participants stated they wished their principal would "observe me working with kids," and "be there when you need to talk and answer questions without making you feel like you are bugging him." Many of these institutions only have one administrator to deal with all of the administrative duties. Principals who have to manage all of these roles find themselves devoting less time to their teachers. If policies were in place, and resources available, to cap the amount of duties assigned to one principal, the amount of time they could spend observing, collaborating, and guiding their teachers could increase. Also, hiring assistant principals or deans would have a positive effect on the time principals spend providing emotional, technical, instructional, and environmental support to their teachers.

\section{References}

Ax, M., Conderman, G., \& Stephens, J. T. (2001). Principal support essential for retaining special educators. NASSP Bulletin, 85(621), 66-71. http://dx.doi.org/10.1177/019263650108562108

Balfour, C. Y. (2001). Impact of certification status on the administrative support needs of novice special education teachers. (Unpublished doctoral dissertation). George Mason University, Fairfax, VA.

Berry, B. (2004). Recruiting and retaining highly qualified teachers for hard to staff schools. NASSP Bulletin, 88(638), 5-27. http://dx.doi.org/10.1177/019263650408863802

Billingsley, B. S. (2004). Special education teacher retention and attrition: A critical analysis of the research literature. The Journal of Special Education, 38(1), 39-55. http://dx.doi.org/10.1177/00224669040380010401

Billingsley, B. S., \& Cross, L. H. (1992). Predictors of commitment, job satisfaction, and intent to stay in teaching: A comparison of general and special educators. The Journal of Special Education, 25(4), 453-471. http://dx.doi.org/10.1177/002246699202500404

Brown, K. M., \& Wynn, S. R. (2009). Finding, supporting, and keeping: The role of the principal in teacher retention issues. Leadership and Policy in Schools, 8(1), 37-63. http://dx.doi.org/10.1080/15700760701817371 
Cooley, E., \& Yovanoff, P. (1996). Supporting professionals at risk: Evaluating interventions to reduce burnout and improve retention of special educators. Exceptional Children, 62(4), 336-355.

Cozby, P. C. (2007). Methods in behavioral research (9th ed.). New York, NY: McGraw Hill.

Creswell, J. W. (2003). Research design: Qualitative, quantitative, and mixed methods approaches (2nd ed.). London, England: Sage.

George, N. L., \& George, M. (1995). To leave or stay? An exploratory study of teachers of students with emotional and behavioral disorders. Remedial \& Special Education, 16(4), 227-236. http://dx.doi.org/10.1177/074193259501600406

Otto, S. J., \& Arnold, M. (2005). A study of experienced special education teachers' perceptions of administrative support. College Student Journal, 39(2), 253-259.

Pallant, J. (2007). SPSS survival manual (3rd ed.). New York, NY: McGraw Hill.

Varrati, A. M., Lavine, M. E., \& Turner, S. L. (2009). A new conceptual model for principal involvement and professional collaboration in teacher education. Teachers College Record, 111(2), 480-510.

\section{(cc) $\mathrm{BY}$}

This work is licensed under a Creative Commons Attribution 3.0 License. 